Sandra Donkervoort, MS CGC

Diana Bharucha-Goebel, MD

Pomi Yun, MPH

Ying $\mathrm{Hu}, \mathrm{MS}$

Payam Mohassel, MD

Ahmet Hoke, MD, PhD

Wadih M. Zein, MD

Daniel Ezzo, BS

Andrea M. Atherton, MS, CGC

Ann C. Modrcin, MD

Majed Dasouki, MD

A. Reghan Foley, MD

Carsten G. Bönnemann, MD

Correspondence to

Dr. Bönnemann:

carsten.bonnemann@nih.gov

Supplemental data at Neurology.org/ng

\section{HSP and deafness}

\section{Neurocristopathy caused by a novel mosaic SOX10 mutation}

\section{OPEN}

\section{ABSTRACT}

Objective: To identify the underlying genetic cause in 2 sisters affected with progressive lower extremity spasticity, neuropathy, and early-onset deafness.

Methods: Whole-exome sequencing was performed, and segregation testing of variants was investigated using targeted Sanger sequencing. An inherited paternal mosaic mutation was further evaluated through quantitative analysis of the ratio of mutant vs wild-type allele in genomic DNA from various tissues, including blood, dermal fibroblasts, and saliva.

Results: A novel heterozygous nonsense mutation (c.1140C >A; p.Y380X) in SOX10 was identified in the affected sisters. Paternal mosaicism was suspected based on a small chromatogram peak, which was less than the heterozygous peak of the mutated allele. Consistent with mosaicism, the mosaic paternal samples had notable variability in the ratio of mutant vs wild-type allele in various tissues (compared with the fully heterozygous daughter), with the highest paternal mutant levels in saliva (32.7\%) and lowest in dermal fibroblasts (13.9\%). Targeted clinical re-examination of the father revealed a sensorimotor neuropathy that was previously clinically unrecognized.

Conclusions: These findings expand the phenotypic spectrum of SOX10-related neurocristopathy. Mutations in SOX10 should be considered in patients presenting with a complicated form of hereditary spastic paraplegia that includes neuropathy and deafness. Diagnostic workup may be complicated, as SOX10 mutations can present in a mosaic state, with a mild clinical manifestation. Neurol Genet 2017;3:e151; doi: 10.1212/NXG.0000000000000151

\section{GLOSSARY}

$\mathbf{C V}=$ conduction velocity; $\mathbf{H S P}=$ hereditary spastic paraplegia; $\mathbf{N C C}=$ neural crest cell; $\mathbf{N M D}=$ nonsense-mediated decay; $\mathbf{R T}=$ real time; $\mathbf{S R Y}=$ sex determining region $\mathbf{Y} ; \mathbf{W S 4}=$ Waardenburg syndrome type $4 ; \mathbf{W} \mathbf{T}=$ wild type.

SOX10 (SRY [sex determining region Y]-box 10) is a SRY-related transcription factor that plays a critical role in the early development of the pluripotent neural crest lineage and is necessary for cell fate determination and cell lineage development. ${ }^{1-3}$ These cell types include neurons and glia of the peripheral nervous system, Schwann cells, enteric neurons, facial skeleton and connective tissues, and melanocytes of the skin and of the inner ear. ${ }^{4-6} \mathrm{~A}$ defect in the neural crest cell (NCC) lineage can cause a clinical and genetic heterogeneous group of NCC disorders known as neurocristopathies. ${ }^{7-9}$

Historically, SOX10 mutations were known to cause a relatively restricted auditorypigmentary phenotype known as Waardenburg syndrome type 4C (WS4), manifesting as Waardenburg syndrome with Hirschsprung disease (OMIM 613266)..$^{10,11}$ It was not until more recently that a distinct neurologic phenotype resulting from SOX10 mutations was recognized, which includes peripheral demyelinating neuropathy, central dysmyelinating leukodystrophy, Waardenburg syndrome and Hirschsprung disease (PCWH, OMIM

From the Neuromuscular and Neurogenetic Disorders of Childhood Section (S.D., D.B.-G., P.Y., Y.H., P.M., D.E., A.R.F., C.G.B.), and National Eye Institute (W.M.Z.), National Institutes of Health, Bethesda, MD; Children's National Medical Center (D.B.-G.), Washington, DC; Department of Neurology (A.H.), The Johns Hopkins University School of Medicine, Baltimore, MD; Children's Mercy Hospital (A.M.A., A.C.M.), Kansas City, MO; and Department of Neurology (M.D.), University of Kansas Medical Center, Kansas City, KS.

Funding information and disclosures are provided at the end of the article. Go to Neurology.org/ng for full disclosure forms. The Article Processing Charge was funded by the authors.

This is an open access article distributed under the terms of the Creative Commons Attribution-NonCommercial-NoDerivatives License 4.0 (CC BY-NC-ND), which permits downloading and sharing the work provided it is properly cited. The work cannot be changed in any way or used commercially without permission from the journal. 
609136). ${ }^{9}$ Here, we present 2 sisters with a unique presentation of early-onset bilateral sensorineural hearing loss, progressive distal lower extremity spasticity, hypomyelinating sensorimotor neuropathy, mild pigmentary abnormalities, and normal cognition. A novel truncating mutation in SOX10 was identified in each sister through exome sequencing and was found to be inherited from a mosaic father. Somatic mosaicism was confirmed through quantitative analysis of the relative ratio of the mutant allele in blood (23.3\%), dermal fibroblasts (13.9\%), and saliva $(32.7 \%)$.

METHODS Standard protocol approvals, registrations, and patient consents. The study was approved by the Institutional Review Board of the National Institute of Neurological Disorders and Stroke, NIH (Protocol 12-N-0095). Written informed consent and appropriate assent were obtained by a qualified investigator. Medical history was obtained, and clinical evaluations were performed as part of the standard neurologic and ophthalmologic evaluations. Genomic DNA was obtained from blood, saliva, and dermal fibroblasts based on standard procedures. Muscle and nerve biopsies were obtained as part of the

\section{Figure $1 \quad$ Clinical findings}

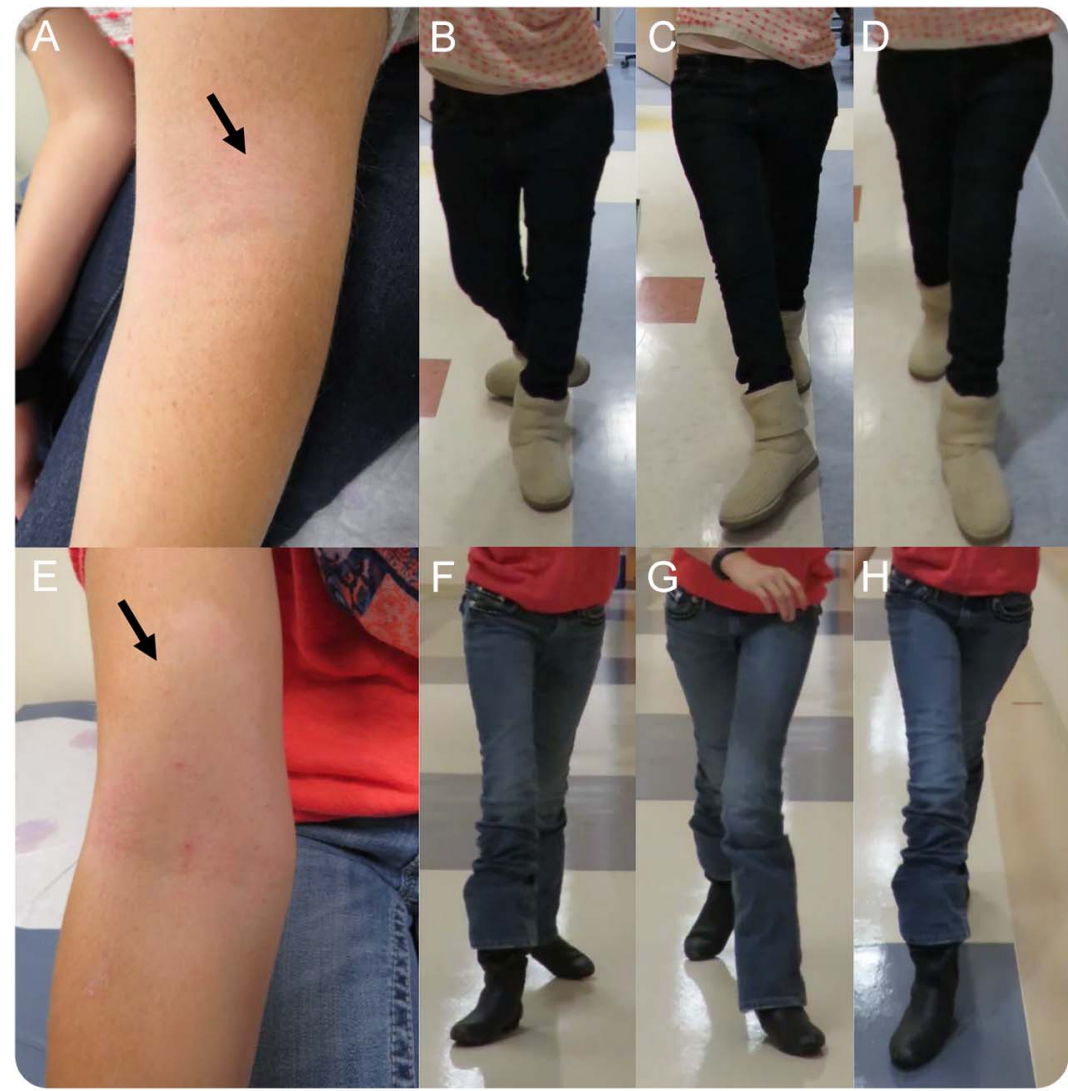

Cutaneous hypopigmentation is seen in $\mathrm{P} 1(\mathrm{~A})$ and $\mathrm{P} 2(\mathrm{E})$. Photographs demonstrating scissoring-type gait with evidence of proximal lower extremity weakness in $P 1$ (B-D) and P2 (F-H). regular clinical diagnostic workup and were evaluated by standard light and electron microscopy protocols.

Mutation detection. Whole-exome sequencing on blood samples obtained from patient 1 (P1), patient 2 (P2), 1 unaffected brother, and the parents was performed at the NIH Intramural Sequencing Center using the Illumina (San Diego, CA) TruSeq Exome Enrichment Kit, and Illumina HiSeq 2500 sequencing instruments. Variants were analyzed using VarSifter ${ }^{12}$ and searched for in the National Heart, Lung, and Blood Institute Exome Sequencing Project database (evs.gs.washington.edu/EVS/) and Exome Aggregation Consortium database (exac.broadinstitute. org). PCR amplification of exon 4 of SOX10 in the complete family was followed by Sanger sequencing on an ABI $3130 \times 1$ capillary sequencer, in forward and reverse directions. Results were then confirmed in an outside Clinical Laboratory Improvement Amendment-certified laboratory.

Quantification of mutant vs normal allele. Genomic DNA was extracted from blood, dermal fibroblasts, and saliva using Custom TaqMan SNP Genotyping Assays (Life Technologies, Grand Island, NY), consisting of mutation-specific primers, and fluorescent-labeled allele discrimination probes were designed for the mutation using a custom design tool provided by Applied Biosystems (Grand Island, NY [table e-1 at Neurology. org/ng]). Twenty-five nanograms of genomic DNA was used with total volume of $5 \mu \mathrm{L}$ for each reaction. The master mix was ordered from the manufacturer (4371353; Life Technologies, Grand Island, NY). The fluorescent readings were recorded after 40 amplification cycles. The amplification was performed using the QuantStudio 6 Flex real-time (RT) PCR system (Applied Biosystems), and signals were recorded by QuantStudio Realtime PCR software v1.1. Reactions were run in triplicates. COL6A1 was used as an endogenous quantity control for the samples. Quantitative analysis of the percentage of mosaicism was performed as previously reported. ${ }^{13}$ Mutant allele quantities were calculated by using the $\Delta \Delta$ cycle threshold $(\Delta \Delta \mathrm{Ct}$ ) method: $\Delta \Delta \mathrm{Ct}=\Delta \mathrm{Ct}$ (mosaic) $-\Delta \mathrm{Ct}$ (het). ( $\Delta \mathrm{Ct}$ was defined as the difference between the mean $\mathrm{Ct}$ values of mutant and wild type [WT].)

RESULTS Case report. Patient 1 (P1) is a 19-year-old woman with a history of lower extremity spasticity, neuropathy, and bilateral early-onset deafness who presented for diagnostic evaluation. First concerns arose prenatally with reduced fetal movements. The hearing loss was first recognized at 2 months of age, and brain MRI revealed the absence of the semicircular canals bilaterally. She had early gross motor delays and began walking with an unsteady gait at 3 years of age. By 7 years of age, she had developed a prominent waddling-type gait, bilateral foot drop, and had frequent falls. By 9 years of age, she could only ambulate short distances independently, and by 13 years of age, she was unable to walk independently without assistance. Progressive lower extremity spasticity has been noted since 16 years of age. P1 reportedly had evidence of some early fine motor difficulties. She has no history of seizures or learning difficulties. She has a history of urinary urgency and constipation (with no history of Hirschsprung disease). 
Neurologic examination at 19 years of age revealed mild dysmorphic facial features, including a higharched palate, a small-sized mouth, and thin, upturned nostrils. There was evidence of a kyphotic posture. Skin examination was notable for areas of hypopigmentation on the face and the flexor surfaces of the elbows (figure 1A). There was a head tremor at rest. Extraocular movements were full. Occasional fine nystagmus was noted during funduscopic examination only. Facial strength was normal. Upper extremity strength was approximately $5 / 5$ (the Medical Research Council grade) except for the thumb abduction which was $4+15$, and lower extremity strength was in the 5-/5 range. Sensation was reduced to pinprick and vibration in a lengthdependent fashion. Proprioception was normal.
Reflexes were absent at the biceps and Achilles tendons bilaterally, $1+$ at the brachioradialis, and $3+$ at the patellae bilaterally. Babinski response was equivocal. There was prominent lower extremity spasticity with evidence of a spastic catch bilaterally. Ambulation was dependent on full truncal support. She had a scissoring gait with circumduction of the legs and bilateral foot drop (figure 1, B-D). Rapid alternating movements were slow with reduced amplitude and evidence of mirror movements. There was dysmetria on finger-to-nose testing which was increased with eyes closed (fixed target).

Nerve conduction studies (19 years of age) were consistent with a demyelinating sensory and motor neuropathy, evidenced by diffuse, symmetric reduction in nerve conduction velocities (CVs) (peroneal

Figure 2 Chronic hypomyelinating neuropathy
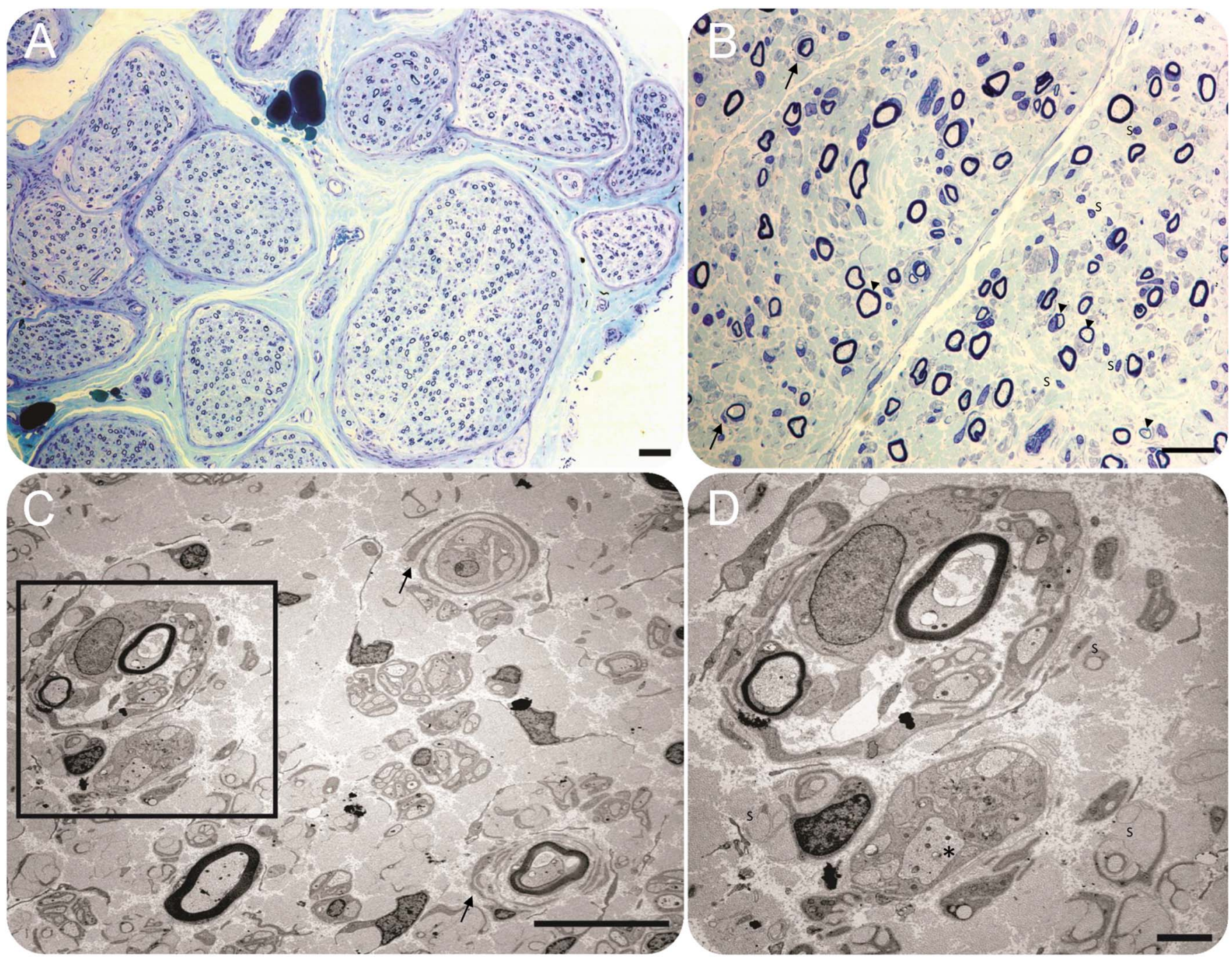

Plastic-embedded semithin sections (A and B) show a uniform reduction in large and small myelinated fiber density in P1. Several thinly myelinated fibers (arrowheads) and a few primordial onion bulb formations are present (arrows). Multiple empty Schwann cell nuclei are seen (S). Electron microscopy images $(C$ and $D)$ show similar findings. An onion bulb ( $C$, lower right arrow) and an empty onion ( $C$, upper right arrow) are highlighted. $D$ is a higher magnification image of the area of the box in C. There are several empty Schwann cells and Remak bundles (S), suggestive of loss of unmyelinated fibers. Some larger axons appear to have no myelin (*), suggestive of defective myelination. (Scale bars: A: $50 \mu \mathrm{m}, \mathrm{B}: 20 \mu \mathrm{m}, \mathrm{C}: 10 \mu \mathrm{m}$, and D: $2 \mu \mathrm{m}$.) 
Figure 3 Ophthalmologic findings

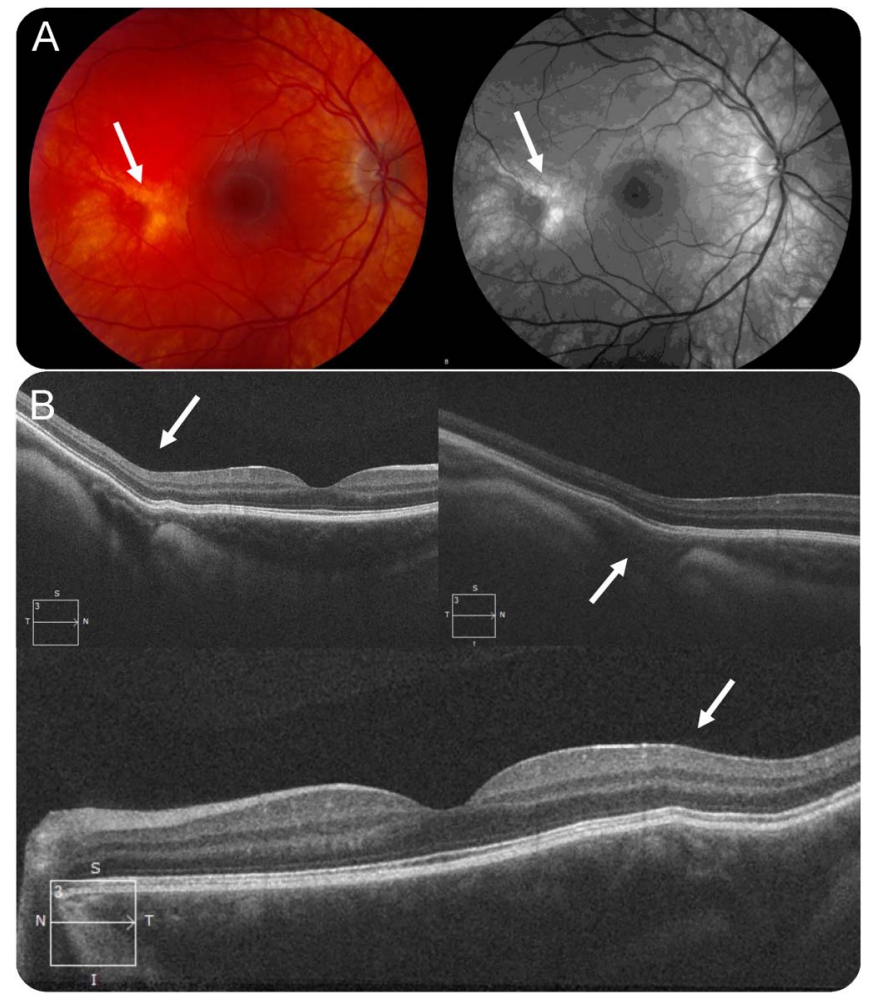

(A) Color and red-free fundus photography of the right eye of P1 showing pigmentary changes in a localized area temporal to the macula. Arrows point at the area of patchy hypopigmentation corresponding to the changes noted on optical coherence tomography. (B) Optical coherence tomography of P1 indicating an irregular bowing back of the retina (arrows) with a change in the reflectance of the choroid in the area corresponding to the pigmentary changes noted on examination. There is no interruption of the retinal layers and no loss of retinal cells. fetal movements in utero as well as breech position at delivery. She was diagnosed with profound sensorineural hearing loss at 12 months of age, and brain MRI performed in infancy reportedly revealed the absence of 1 semicircular canal. P2 also has a history of delayed gross motor development (walking independently at $2 \frac{1}{2}$ years of age) and mild early fine motor difficulties. She was noted to have a widebased gait at $2 \frac{1}{2} 2$ years of age, developed spasticity over time, and by 9 years of age was using a wheelchair for longer distances. At 15 years of age, she can ambulate with minimal assistance (figure $1, \mathrm{~F}-\mathrm{H}$ ). She had been diagnosed with a progressive demyelinating sensorimotor neuropathy. On examination, upper extremity strength was approximately $5 / 5$ except for finger extension and thumb abduction which were $4+15$. Lower extremity strength was subgravity in hip flexion, hip abduction, hip adduction, dorsiflexion, eversion, plantarflexion, and inversion. Sensation was reduced to pinprick and vibration in a length-dependent fashion. Proprioception was normal. Reflexes were absent at the biceps and Achilles tendons bilaterally, $1+$ at the brachioradialis, and $4+$ at the patellae bilaterally with cross-adductor spread. There was a spastic catch in the bilateral lower extremities. Rapid alternating movements were slow with reduced amplitude. There was evidence of dysmetria with eyes closed only. Skin examination was notable for multiple areas of hypopigmentation (figure 1E). Detailed clinical information for both sisters is summarized in table 1.

P1 and P2's mother and father did not report any motor: CV $11.7 \mathrm{~m} / \mathrm{s}$ with amplitude $1.5 \mathrm{mV}$; tibial motor: CV $19.4 \mathrm{~m} / \mathrm{s}$ with amplitude $2.3 \mathrm{mV}$ ) and prolonged distal latencies. A sural nerve biopsy performed at 8 years of age was consistent with a chronic predominantly hypomyelinating neuropathy (figure 2 ), and muscle biopsy of the quadriceps performed at the same time was suggestive of neurogenic changes with evidence of fiber-type grouping. X-ray of the spine showed a 14-degree curvature of the thoracic and lumbar spine from T11 to L3.

Fundoscopic examination at age 19 years showed a well-developed foveal structure but with evidence of bilateral patches of thinning and anomalous pigmentation (mostly depigmented) temporal to the central macula (figure 3A). Optical coherence tomography indicated bowing out of the retina/choroid underlying the patchy areas of anomalous pigmentation (figure 3B), suggestive of a developmental anomaly of embryogenesis likely affecting the sclera in those regions.

Patient 2 (P2) is a 15-year-old girl and the younger sister of P1. Family history is shown in figure 4 . She presented similarly to her sister with decreased symptoms. On further questioning, however, the 39year-old father (P3) reported a history of frequent ankle sprains, apparent high-arched feet, and mild hammertoe deformities, suggestive of a chronic neuropathy of likely genetic etiology. On neurologic examination, he was found to have a symmetric, length-dependent sensory greater than motor neuropathy with reduction of pain and vibration sensation in the distal lower extremities. He had reduced reflexes throughout, including in the upper extremities (table 1). Proprioception was normal. His ophthalmologic examination was unremarkable except for mild myopia. Nerve conduction studies showed absent sural sensory nerve action potential, suggesting the possibility of an existing neuropathy given the absent response at his age. He was found to have baseline sinus bradycardia and orthostasis (with an increase in the heart rate by more than 20 beats when transitioning from supine to standing), which may be suggestive of a mild autonomic neuropathy as well. Other quantitative autonomic testing was unremarkable. Detailed clinical information can be found in appendix e-1. 


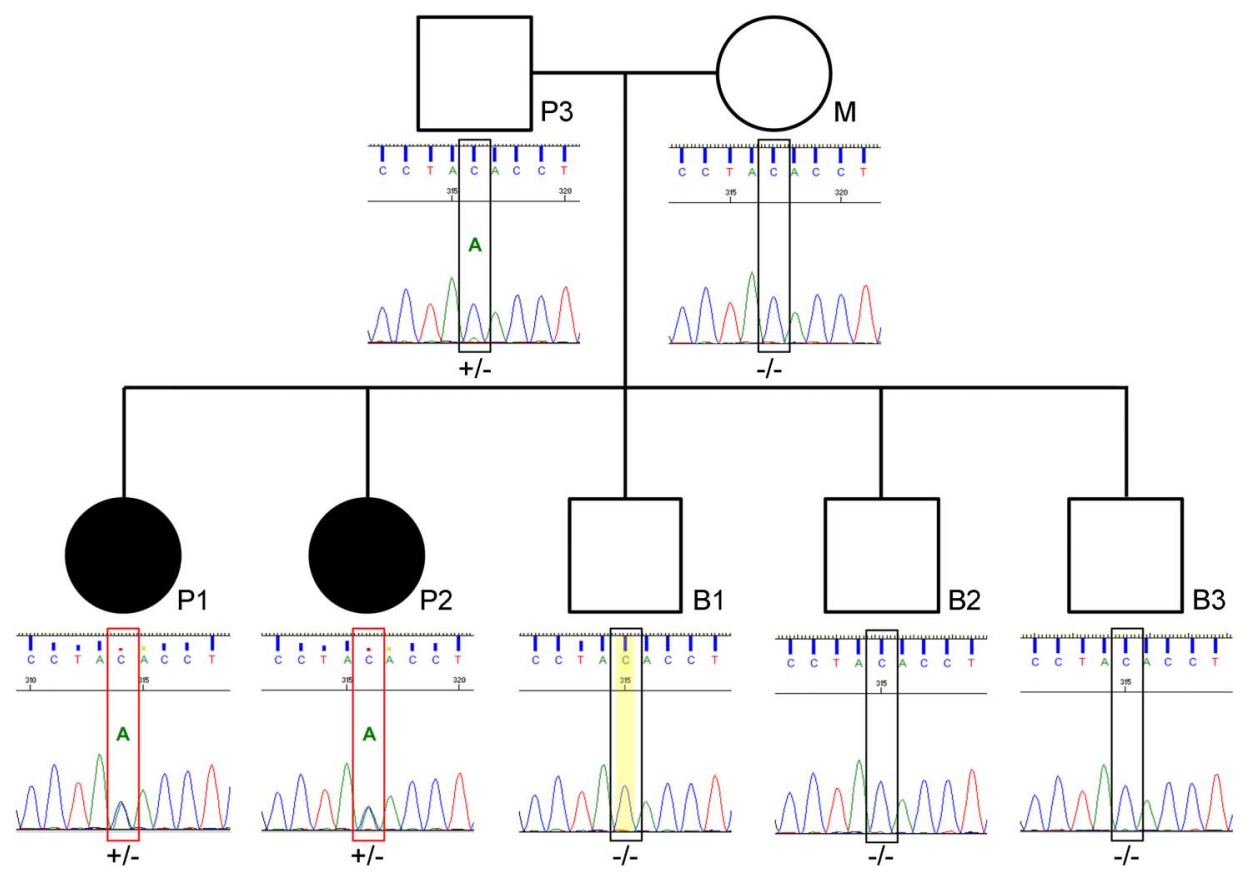

Family history showing the mosaic father (P3), his unaffected spouse (M), the 2 affected daughters (P1 and P2), and 3 unaffected sons (B1, B2, and B3). Genomic DNA sequence chromatograms show the somatic c.1140C $>A ; p . Y 380 X$ SOX10 mutation in the mosaic father and 2 affected daughters. The mosaic mutation sequence is seen as a lower-height peak in parent (P3) compared to the fully heterozygous mutation in the affected children P1 and P2.

Identification of a SOX10 mutation. Exome sequencing identified a heterozygous mutation in SOX10: (c.1140C >A [p.Y380X] [NM_006941.3]) in both sisters. This nonsense mutation was not present in the control database of the National Heart, Lung, and Blood Institute Exome Sequencing Project and Exome Aggregation Consortium. The mutation was confirmed through Sanger sequencing, and familial segregation studies were negative in the 3 asymptomatic brothers of P1 and P2 and their mother. Paternal mosaicism was suspected because a small peak of the mutated allele was observed in the father's chromatogram (figure 4).

Mutant vs normal allele quantification. To confirm and determine the degree of paternal mosaicism, the relative ratio of the mutant allele in the father was analyzed in different somatic tissues, with 3 pairs of RT PCR probes specific to either SOX10 mutant or WT allele. Genomic DNA from saliva showed the highest proportion of approximately $32.7 \%$ of the mutant allele, while the mutant ratio was $23.3 \%$ in peripheral blood and $13.9 \%$ in dermal fibroblasts.

DISCUSSION Here, we present 2 sisters with a unique phenotype of complicated hereditary spastic paraplegia (HSP) manifesting as progressive lower extremity spasticity, demyelinating neuropathy, and early-onset sensorineural hearing loss with normal cognition, resulting from a novel mutation in SOX10.
Paternal mosaicism was confirmed through quantitative RT-PCR analysis of mutant allele vs WT allele in blood, dermal fibroblasts, and saliva in the affected patients compared with the mosaic and control parent. Although no symptoms were volunteered by the parent with the mosaicism, on careful clinical evaluation, he was found to have a mild sensory neuropathy and mild autonomic dysfunction.

Mosaicism is a result of a postzygotic mitotic mutational event with the mutation confined to somatic cells (somatic mosaicism), germline cells (gonadal mosaicism), or both, depending on the developmental stage and lineage at which the event occurred. The clinical manifestations of somatic mosaicism are highly variable and depend on the type of mutation, the tissue distribution, and the relative mutation load. Recent advances in genetic technologies have shown that parental mosaicism underlying the transmission of mutations from parents without a clinical phenotype to children with a simplex genetic disorder is more common than previously appreciated. ${ }^{14}$ Mosaicism can thus complicate the diagnostic workup and the goal of providing accurate genetic counseling.

The known neurologic manifestations of SOX10-related neurocristopathy include peripheral demyelinating neuropathy, central dysmyelinating leukodystrophy, Waardenburg syndrome, and Hirschsprung disease (PCWH). Spasticity is rare, having been reported in 4 different patients and at 
Table 1 Clinical findings

\begin{tabular}{|c|c|c|c|}
\hline Patient/sex & $\mathrm{P} 1 / \mathrm{F}$ & $\mathrm{P} 2 / \mathrm{F}$ & $\mathrm{P} 3 / \mathrm{M}$ \\
\hline soX10 mutation & c. $1140 \mathrm{C}>\mathrm{A} ; \mathrm{p} . \mathrm{Y} 380 \mathrm{X}$ & c. $1140 \mathrm{C}>\mathrm{A} ; \mathrm{p} . \mathrm{Y} 380 \mathrm{X}$ & c. $1140 \mathrm{C}>\mathrm{A} ; \mathrm{p} . \mathrm{Y} 380 \mathrm{X}$ \\
\hline Mutation status & Heterozygous & Heterozygous & Mosaic \\
\hline Fetal movements/birth & Reduced/uncomplicated & Reduced/C-section (breech) & NA \\
\hline Gross motor development & $\begin{array}{l}\text { Sat } 10 \mathrm{mo} \text {; walked } 21 / 2 \text { y; unsteady } \\
\text { gait } 7 \mathrm{y} \text {; lost independent ambulation } \\
13 \mathrm{y}\end{array}$ & $\begin{array}{l}\text { Sat } 10 \mathrm{mo} \text {; walked } 2 \frac{1}{2} \mathrm{y} \text {; decreased } \\
\text { endurance } 10 \mathrm{y}\end{array}$ & $\mathrm{NL}$ \\
\hline Speech delay & + & - & - \\
\hline EMG/NCS (age study) & $\begin{array}{l}\text { Severe demyelinating sensorimotor } \\
\text { polyneuropathy (CV range } 10-31 \mathrm{~m} / \mathrm{s}) ; \\
\text { needle EMG with mixed myopathic and } \\
\text { neurogenic MUPs (19 y) }\end{array}$ & $\begin{array}{l}\text { Moderate demyelinating } \\
\text { sensorimotor polyneuropathy (CV } \\
\text { range } 18-27 \mathrm{~m} / \mathrm{s}) \text {; needle EMG with } \\
\text { myopathic recruitment/MUPs (11 y) }\end{array}$ & $\begin{array}{l}\text { Mild distal sensory neuropathy (CV } \\
\text { range } 38-61 \mathrm{~m} / \mathrm{s}) \text {; needle EMG NL } \\
(39 \mathrm{y})\end{array}$ \\
\hline Brain MRI (age of study) & $\begin{array}{l}\text { Absence of semicircular canals; } \\
\text { normal brain }(2 \mathrm{y}) \text {; images not } \\
\text { available for rereview }\end{array}$ & $\begin{array}{l}\text { Absence of } 1 \text { semicircular canal; } \\
\text { normal brain }(10 \text { mo); images not } \\
\text { available for rereview }\end{array}$ & NL (39 y) \\
\hline Constipation/Hirschsprung disease & + + - & $+1-$ & $-1-$ \\
\hline Hearing loss/age at diagnosis/type & $\begin{array}{l}\text { Severe (bilateral)/2 mo/Mondini } \\
\text { malformation and absence of the } \\
\text { semicircular canals }\end{array}$ & $\begin{array}{l}\text { Severe (bilateral)/newborn screen/ } \\
\text { Mondini malformation and absence of } \\
1 \text { semicircular canal }\end{array}$ & $-I-I-$ \\
\hline Cochlear implants/ (age) & $+(26 \mathrm{mo})$ & $+(12 \mathrm{mo})$ & - INA \\
\hline Nystagmus & $\begin{array}{l}\text { Horizontal bilateral nystagmus noted } \\
\text { at } 1 \mathrm{mo} \text {, resolved at } 3 \mathrm{y}\end{array}$ & Noted at $5 w k$, resolved at $3 y$ & - \\
\hline Bright blue irides/iris heterochromia & $-1-$ & $-I-$ & $-1-$ \\
\hline Hypopigmentation (eyes) & $\begin{array}{l}\text { Pigmentary change temporal to } \\
\text { macula }\end{array}$ & $\begin{array}{l}\text { Pigmentary change temporal to } \\
\text { macula }\end{array}$ & - \\
\hline Hypopigmentation (skin) & Cubital fossae, cheeks & $\begin{array}{l}\text { Cheeks, neck, upper chest, cubital } \\
\text { fossae, back }\end{array}$ & - \\
\hline
\end{tabular}

Abbreviations: $+=$ present; $-=$ absent; $C V=$ conduction velocity; $F=$ female; $M=$ male; MUP = motor unit potential; NA = not available; NCS = nerve conduction study; $\mathrm{NL}=$ normal; UE = upper extremities.

times associated with additional PCWH manifestations including seizures and cognitive impairment, features which were notably absent in our patients. ${ }^{9,15,16}$ Moreover, our patients did not have distinct symptoms of Waardenburg syndrome or Hirschsprung disease. Both sisters have a history of constipation, and after deep phenotyping, cutaneous and macular hypopigmentation were identified in both, compatible with a "forme fruste" of Waardenburg syndrome.

The SOX10 gene consists of 5 exons and contains a high mobility group, a DNA-binding domain and a C-terminal transactivation domain. ${ }^{17}$ Truncating SOX10 mutations can lead to PCWH or WS4, and recent work has suggested that the 2 distinct phenotypes may be explained by 2 different molecular pathogenic mechanisms. ${ }^{9}$ Truncating mutations in any exons, except the last one, lead to mutant mRNA which is recognized and degraded through nonsense-mediated decay (NMD). This results in haploinsufficiency, which causes the restricted and classic WS4 phenotype of Waardenburg syndrome and Hirschsprung disease, without peripheral or CNS involvement. By contrast, mutations in the last exon escape NMD and generate a stable truncated SOX10 mutant protein with increased DNAbinding affinity, which acts in a dominant-negative manner, and cause the severe PCWH neurocristopathy with neurologic manifestations. More proximal mutations within exon 5 (Q234X, Q250X, and S251X) exhibit a stronger dominant-negative effect and lead to more severe congenital-onset symptoms and possible neonatal death. ${ }^{18-20}$ The novel mutation (Y380X) identified in our family is very close to the C-terminal end of SOX10, with only 2 mutations reported that are more distal': the X467K mutation, which was identified in a patient with severe motor and cognitive delays, and the 1400del12 mutation, which was found in a patient with complete deficiency of brain myelination and seizures who never 
reached independent ambulation. ${ }^{16,21}$ It is of interest that in our family, the Y380X mutation is not associated with cognitive impairment or seizures, indicating that there may be other protective factors at play.

SOX10 is involved in the early development of the NCCs and is involved in Schwann cells and oligodendrocytes later in development as well as into adulthood. ${ }^{17}$ Sural nerve pathology in patient 1 showed findings consistent with a chronic hypomyelinating neuropathy with reduction of myelinated fibers and defective myelination of axons. Because of the presence of cochlear implants, both sisters were unable to undergo brain MRI to evaluate for possible central demyelination. The progressive weakness and spasticity seen in these 2 patients may potentially suggest a role of SOX10 that is not only restricted to periods of neural development but is also involved in the production and maintenance of myelin and axonal health.

An understanding of the underlying pathogenic disease mechanism is essential for developing targeted therapeutic interventions. Clinical and genetic data evaluated in this family show that a reduction in the relative dose of the mutant allele, as seen in the mosaic parent, ameliorates the clinical severity, indicating that as a therapeutic approach in $\mathrm{PCWH}$, knockdown of the mutant allele expression could be achieved through antisense-mediated or RNAi-based therapy. Careful titration is essential, as haploinsufficiency leads to the classic WS4 phenotype. The WS4 presentation may be more developmental in origin; therefore, the presence of haploinsufficiency postnatally (as induced via allele-specific knockdown) may have less of a clinical effect. Moreover, this approach may potentially only alleviate the progressive neuromuscular symptoms, as the classic WS4 symptoms are present at birth.

Based on this family history of 2 affected sisters born to apparently unaffected parents, autosomal recessive inheritance was initially suspected, and the family was counseled accordingly. A confirmed genetic diagnosis allowed for accurate genetic counseling as the recurrence risk in future pregnancies of the patients is $50 \%$, which is higher than that previously anticipated. Genetic counseling for the mosaic parent (the father) was more complicated, as recurrence risk depends on the ratio of mutated germline progenitor cells, which cannot be predicted from analysis of somatic tissues. In addition to his 2 affected daughters, the mosaic parent at present has 3 unaffected children. In reviewing families with parental mosaicism for dominant mutations causing osteogenesis imperfecta and retinoblastoma, the recurrence rate was estimated to be $27 \%$ and $10 \%$, respectively. ${ }^{22,23}$ Caution is necessary when counseling for somatic mosaicism, as an individual's recurrence risk may be as high as $50 \%$.
We have presented 2 sisters with a unique phenotype of early-onset bilateral sensorineural hearing loss, progressive distal lower extremity spasticity, demyelinating sensorimotor neuropathy, mild pigmentary abnormalities, and normal cognition. Our report expands the phenotypic spectrum of $S O X 10$-related neurocristopathy. $\mathrm{Mu}$ tations in $S O X 10$ should be considered in patients presenting with a phenotype of complicated HSP with hypomyelinating neuropathy and deafness, while SOX10 somatic mosaicism may manifest with only a mild sensory neuropathy.

\section{AUTHOR CONTRIBUTIONS}

S. Donkervoort: study concept and design, analysis, interpretation of genetic and clinical data, and drafting manuscript. D. Bharucha-Goebel and P. Yun: acquisition and interpretation of clinical data and revision of manuscript. Y. Hu: analysis and interpretation of genetic data. P. Mohassel, A. Hoke, W.M. Zein, AM. Atherton, AC Modrcin, and M Dasouki: acquisition and interpretation of clinical and biopsy data. AR Foley and C.G. Bönnemann: supervising the acquisition and interpretation of clinical and genetic data and critical revision of the manuscript for important intellectual content. All authors critically reviewed and approved the final manuscript.

\section{ACKNOWLEDGMENT}

The authors thank the family for their participation in the study. They thank the NIH Intramural Sequencing Center and Dr. Hakonarson and Dr. Guo from The Center of Applied Genomics, Children's Hospital of Philadelphia, for performing the exome sequencing. They thank Dr. Anne Rutkowski and CureCMD for their help with patient recruitment.

\section{STUDY FUNDING}

Work in C.G. Bönnemann's laboratory is supported by intramural funds by the National Institute for Neurological Disorders and Stroke/NIH. Exome sequencing was funded through the Clinical Center Genomics Opportunity (CCGO), which is sponsored by the National Human Genome Research Institute (NHGRI), the NIH Deputy Director for Intramural Research, and the NIH Clinical Center.

\section{DISCLOSURE}

Dr. Bharucha-Goebel, Mohassel, Hoke, Zein, Modrcin, Dasouki, Foley, Bönnemann, Ms. Donkervoort, Yun, Hu, and Mr. Ezzo report no disclosures. Andrea M. Atherton is now a full-time employee of Shire Pharmaceuticals. Go to Neurology.org/ng for full disclosure forms.

Received September 23, 2016. Accepted in final form March 22, 2017.

\section{REFERENCES}

1. Kim J, Lo L, Dormand E, Anderson DJ. SOX10 maintains multipotency and inhibits neuronal differentiation of neural crest stem cells. Neuron 2003;38:17-31.

2. Southard-Smith EM, Kos L, Pavan WJ. Sox10 mutation disrupts neural crest development in Dom Hirschsprung mouse model. Nat Genet 1998;18:60-64.

3. Kapur RP. Early death of neural crest cells is responsible for total enteric aganglionosis in Sox10(Dom)/Sox10(Dom) mouse embryos. Pediatr Dev Pathol 1999;2:559-569.

4. Le Douarin NM, Kalcheim C. The Neural Crest, 2nd ed. Cambridge, United Kingdom: Cambridge University Press; 1999.

5. Cordero DR, Brugmann S, Chu Y, Bajpai R, Jame M, Helms JA. Cranial neural crest cells on the move: their roles in craniofacial development. Am J Med Genet A 2011;155A:270-279. 
6. Bondurand N, Dastot-Le Moal F, Stanchina L, et al. Deletions at the SOX10 gene locus cause Waardenburg syndrome types 2 and 4. Am J Hum Genet 2007;81:1169-1185.

7. Bolande RP. The neurocristopathies: a unifying concept of disease arising in neural crest maldevelopment. Hum Pathol 1974;5:409-429.

8. Read AP, Newton VE. Waardenburg syndrome. J Med Genet 1997;34:656-665.

9. Inoue K, Khajavi M, Ohyama T, et al. Molecular mechanism for distinct neurological phenotypes conveyed by allelic truncating mutations. Nat Genet 2004;36:361-369.

10. Omenn GS, McKusick VA. The association of Waardenburg syndrome and Hirschsprung megacolon. Am J Med Genet 1979;3:217-223.

11. Pingault V, Bondurand N, Kuhlbrodt K, et al. SOX10 mutations in patients with Waardenburg-Hirschsprung disease. Nat Genet 1998;18:171-173.

12. Teer JK, Green ED, Mullikin JC, Biesecker LG. VarSifter: Visualizing and analyzing exome-scale sequence variation data on a desktop computer. Bioinformatics 2012;28:599-600.

13. Hsu AP, Sowerwine KJ, Lawrence MG, et al. Intermediate phenotypes in patients with autosomal dominant hyperIgE syndrome caused by somatic mosaicism. J Allergy Clin Immunol 2013;131:1586-1593.

14. Campbell IM, Yuan B, Robberecht C, et al. Parental somatic mosaicism is underrecognized and influences recurrence risk of genomic disorders. Am J Hum Genet 2014;95:173-182.

15. Pingault V, Pierre-Louis L, Chaoui A, et al. Phenotypic similarities and differences in patients with a p.Met112Ile mutation in SOX10. Am J Med Genet Part A 2014;164A 2344-2350.
16. Inoue K, Tanabe Y, Lupski JR. Myelin deficiencies in both the central and the peripheral nervous systems associated with a SOX10 mutation. Ann Neurol 1999;46:313-318.

17. Kuhlbrodt K, Herbarth B, Sock E, Hermans-Borgmeyer I, Wegner M. Sox10, a novel transcriptional modulator in glial cells. J Neurosci 1998;18:237-250.

18. Inoue K, Shilo K, Boerkoel CF, et al. Congenital hypomyelinating neuropathy, central dysmyelination, and Waardenburg-Hirschsprung disease: phenotypes linked by SOX10 mutation. Ann Neurol 2002;52:836-842.

19. Pingault V, Girard M, Bondurand N, et al. SOX10 mutations in chronic intestinal pseudo-obstruction suggest a complex physiopathological mechanism. Hum Genet 2002;111:198-206.

20. Touraine RL, Attie-Bitach T, Manceau E, et al. Neurological phenotype in Waardenburg syndrome type 4 correlates with novel SOX10 truncating mutations and expression in developing brain. Am J Hum Genet 2000; 66:1496-1503.

21. Sham MH, Lui VC, Chen BL, Fu M, Tam PK. Novel mutations of SOX10 suggest a dominant negative role in Waardenburg-Shah syndrome. J Med Genet 2001;38: E30.

22. Sippel KC, Fraioli RE, Smith GD, et al. Frequency of somatic and germ-line mosaicism in retinoblastoma: implications for genetic counseling. Am J Hum Genet 1998; 62:610-619.

23. Pyott SM, Pepin MG, Schwarze U, Yang K, Smith G, Byers PH. Recurrence of perinatal lethal osteogenesis imperfecta in sibships: parsing the risk between parental mosaicism for dominant mutations and autosomal recessive inheritance. Genet Med 2011;13:125-130. 


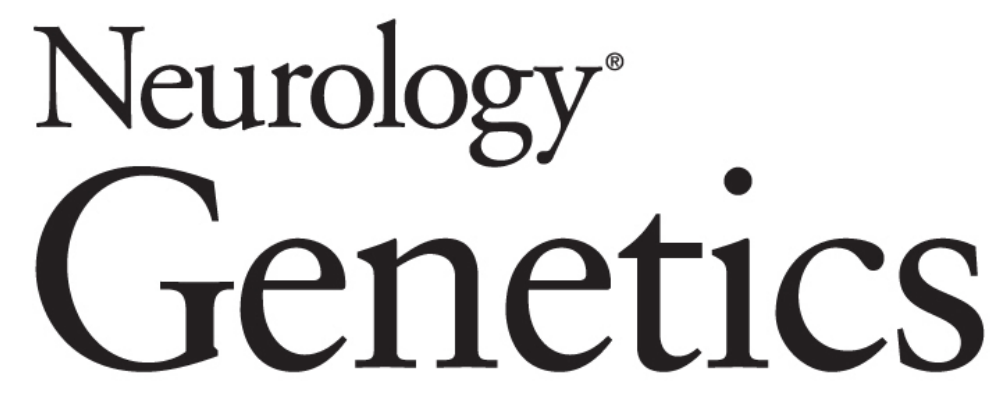

HSP and deafness: Neurocristopathy caused by a novel mosaic SOX10 mutation Sandra Donkervoort, Diana Bharucha-Goebel, Pomi Yun, et al.

Neurol Genet 2017;3;

DOI 10.1212/NXG.0000000000000151

This information is current as of May 15, 2017

Updated Information \&
Services
Supplementary Material
References
Subspecialty Collections

Subspecialty Collections

Permissions \& Licensing

Reprints including high resolution figures, can be found at: http://ng.neurology.org/content/3/3/e151.full.html

Supplementary material can be found at: http://ng.neurology.org/content/suppl/2017/05/15/3.3.e151.DC1

This article cites 22 articles, 2 of which you can access for free at: http://ng.neurology.org/content/3/3/e151.full.html\#\#ref-list-1

This article, along with others on similar topics, appears in the following collection(s):

\section{All Genetics}

http://ng.neurology.org//cgi/collection/all_genetics

Spastic paraplegia

http://ng.neurology.org//cgi/collection/spastic_paraplegia

Information about reproducing this article in parts (figures,tables) or in its entirety can be found online at:

http://ng.neurology.org/misc/about.xhtml\#permissions

Information about ordering reprints can be found online: http://ng.neurology.org/misc/addir.xhtml\#reprintsus

Neurol Genet is an official journal of the American Academy of Neurology. Published since April 2015, it is an open-access, online-only, continuous publication journal. Copyright Copyright @ 2017 The Author(s). Published by Wolters Kluwer Health, Inc. on behalf of the American Academy of Neurology. All rights reserved. Online ISSN: 2376-7839.

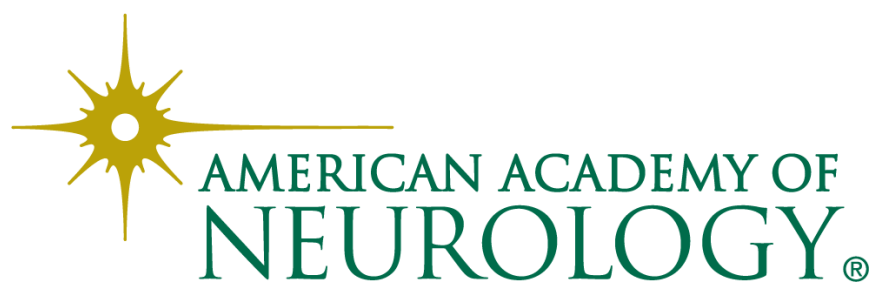

